\title{
TOWARDS BEST PRACTICE IN THE PROMOTION OF PHYSICAL ACTIVITY
}

Bill Bellew

Centre for Disease Prevention and Health Promotion NSW Health Department

his article outlines recent NSW initiatives to promote physical activity. These initiatives comprise:

the establishment of a high-level intersectoral Physical Activity Task Force by the Premier of NSW;

release of the booklet, Towards Best Practice for the Promotion of Physical Activity in the Areas of NSW (1), which was recently published on behalf of the Task Force by the NSW Health Department and the National Centre for Health Promotion; and the establishment of the NSW Physical Activity Demonstration Projects Grants Scheme.

The article also briefly describes "Active Australia", a national collaborative venture involving the Australian Sports Commission, the Commonwealth Department of Health and Family Services, State Departments of Sport and Recreation, local government and the sport and recreation industry. "Active Australia" provides a framework for all physical activity promotion initiatives across the country.

\section{THE PHYSICAL ACTIVITY TASK FORCE}

The Physical Activity Task Force was set up by the NSW Premier in May 1996. It was charged with recommending a comprehensive strategic plan for physical activity in NSW for the period 1997-2002. Task Force members include representatives of the NSW Government Departments of Health, Local Government, School Education, Urban Affairs and Planning, and Sport and Recreation, as well as the National Heart Foundation, Australian Council for Health, Physical Education and Recreation (ACHPER), the fitness industry peak body Fitness NSW, and the National Centre for Health Promotion.

The Task Force's terms of reference are to: develop a comprehensive strategic framework for the promotion of physical activity in NSW in the light of available resources, with specific goals, targets, and delineation of roles and responsibilities; develop a joint action plan identifying lead agencies for the achievement of agreed targets;

consider gaps in current knowledge and the means to address them;

make recommendations for taking the plan forward and for monitoring progress in achieving the specific targets; and

report to Cabinet Office within one year through the Deputy Premier, Minister for Health and Minister for Aboriginal Affairs, in his capacity as Deputy Premier.

The Task Force is chaired by Associate Professor Adrian Bauman, University of NSW, and is supported by a secretariat from the NSW Health Department.

There is a clear recognition that many organisations other than those represented in the membership have an interest in the planning process. The Task Force is ensuring that extensive consultation is incorporated into the schedule of work. For example, in November 1996 a broad consultation retreat was convened with representation of stakeholders from the education, health, sport and recreation, urban and local environment sectors, as well as the fitness industry; inputs were analysed and followed up with core representatives from that consultation process. In February 1997 another consultation retreat was convened, with an explicit focus on the theme of equity and access. Five intersectoral consultation seminars were also planned, to be convened across NSW in March and April 1997. Meetings with other government and non-government stakeholders have been scheduled.

The Task Force has stipulated four generic strategic themes for the strategic planning framework:

\begin{tabular}{l|l} 
nolicy and guideline development; \\
information and education; and \\
monitoring and evaluation.
\end{tabular}

Each of these themes is further subdivided to emphasise the areas where the plan is expected to achieve improvement:

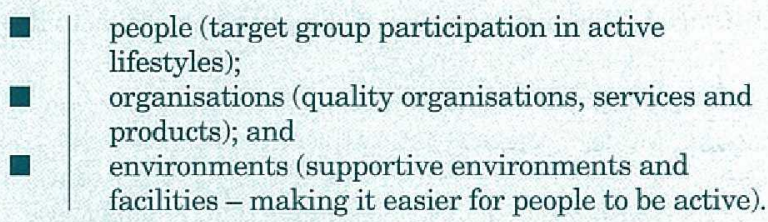

A draft five-year strategic plan will be released for wide public consultation. Comments will be analysed by the secretariat and presented to the Task Force for consideration before the final report is submitted to the Deputy Premier.

Benefits from intersectoral collaboration in the Task Force have already accrued through clearer understanding among the partner organisations of each other's capacity to take action. This has already led to a strengthening of collaborative approaches on specific projects. The final strategic plan will facilitate this collaboration in a sustainable and focused way. The work also links clearly with the new national strategic framework "Active Australia" (see below).

\section{THE BOOKLET, Towards best practice for the promotion of physical activity in the areas of NSW}

The purpose of the booklet is to:
- provide data on the prevalence of physical activity in the NSW population at both Statewide and Area Health Service levels;
- identify priority populations in NSW for intervention; and
- identify best practice approaches to the promotion of physical activity for implementation at local level.

While the booklet recommends vigorous physical exercise for those who are willing and able to undertake it, it recognises that most people simply will not - or cannot exercise strenuously. Therefore the case for moderate physical activity is clearly set out with a population perspective, re-emphasising the special communication and recommendation from the NSW Chief Health Officer that 


\section{Towards best practice}

\section{- Continued from page 13}

"every adult in NSW should accumulate 30 minutes or more of moderate-intensity physical activity on most, preferably all, days of the week".

The data presented in the booklet derive from the 1994 Health Promotion Survey, conducted by telephone with 16,000 adults (aged 18 years and over) living in private households throughout 16 Area and then rural District Health Service clusters in the NSW health system. One component of the survey was designed to measure the prevalence of physical activity, assessing the frequency of participation in walking, light and moderate activity and vigorous physical activities. These data comprise a baseline against which trends in physical activity participation may be monitored in the NSW population.

Sixty-one per cent of males and 42 per cent of females in NSW reported physical activity of a level adequate to improve or maintain their health. There were clearly substantial differences in rates of adequate physical activity between males and females.

Almost half ( 49 per cent) of adults in NSW failed to attain adequate levels of physical activity; this proportion was higher in females ( 58 per cent) than in males ( 40 per cent) and was greater among older age groups than among those aged 18-29 (Figure 2). These differences persisted across socio-economic, regional and other demographic variables (Figure 3). Those who had completed secondary education (52 per cent) or some tertiary education ( 54 per cent) were more likely to have engaged in adequate physical activity than people who had completed primary or some secondary education. Only 41 per cent of people in the lower educational attainment category engaged in adequate physical activity (Figure 4).

An equity perspective suggests that certain groups may have particular barriers to participation, and require innovative physical activity promoting strategies. Priority groups in NSW include older people, women, people from non-English speaking backgrounds, Aboriginal communities and people with young children.

Prevalence data for Area Health Services are also presented in the report, with an analysis of regional variations and suggestions to assist Areas with the establishment of targets and performance indicators.

'Best practice' interventions for Area Health Services are outlined in the report, based on a thorough review of the literature. These are summarised here as seven overall recommendations:

\section{Establish a clear strategic focus}

Promote moderate rather than vigorous intensity activities, concentrating on sedentary or insufficiently-active people rather than those who are already physically active.

\section{Establish clear and achievable goals}

Formulate Area goals, targets and indicators in line with local health needs assessments, addressing priority populations.

\section{Forge key partnerships}

Collaborate with local councils, the Department of Sport and Recreation, and education and other sectors to ensure

\section{FIGURE 2}

PREVALENCE OF ADEQUATE ENERGY EXPENDITURE IN NSW, BY GENDER AND AGE (WEIGHTED TO NSW POPULATION)

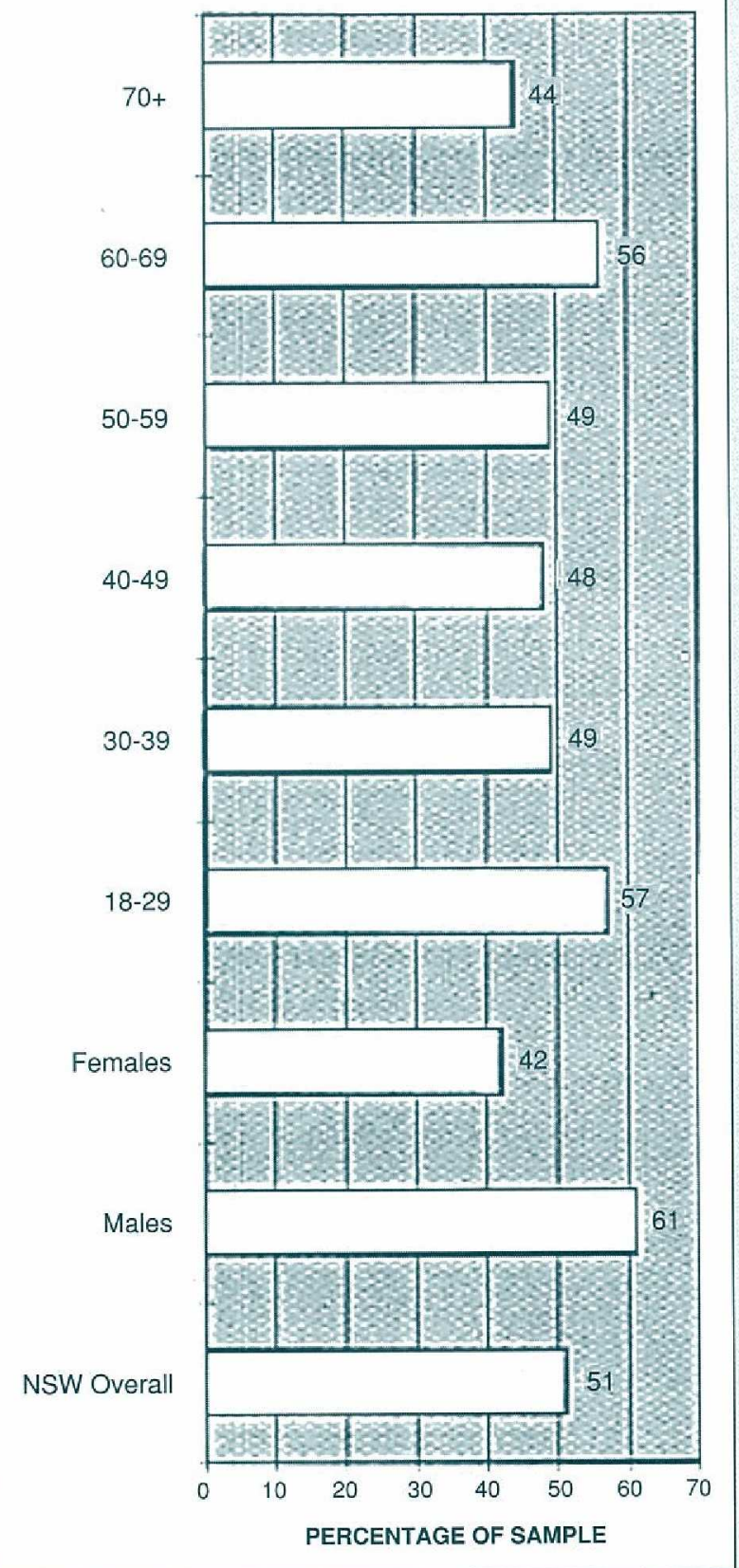

that environments and facilities support community participation in walking and other moderate forms of physical activity; and coordinate action with these key partners to avoid gaps or undesirable duplication of existing service, research or resource provision.

4. Support interventions in primary care settings Encourage provision of advice by general practitioners, other health care providers, and a wide range of other health and fitness professionals about the importance of regular, moderate physical activity. 


\section{FIGURE 3}

PREVALENCE OF ADEOUATE ENERGY EXPENDITURE BY DEMOGRAPHIC VARIABLES (WEIGHTED DATA)

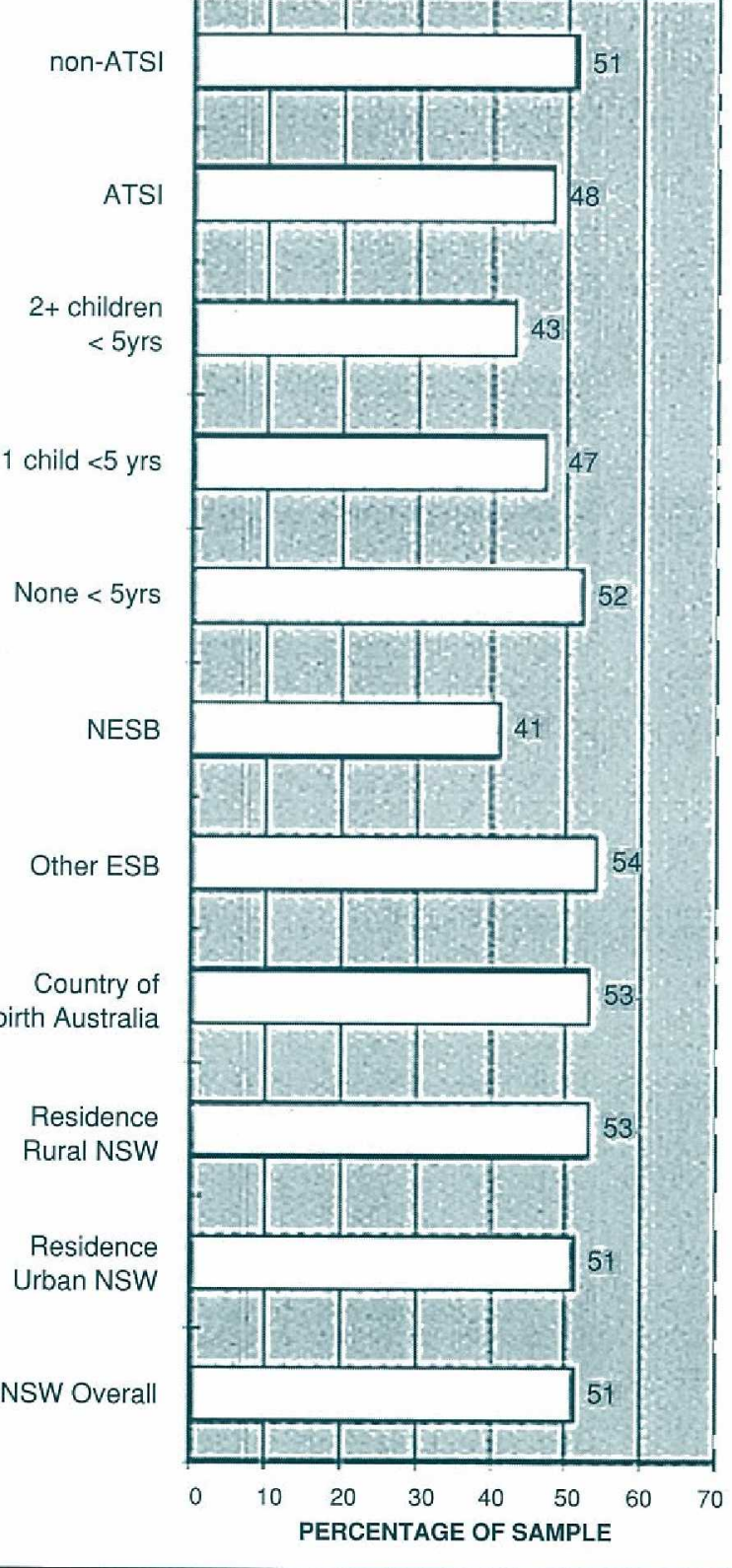

\section{Support interventions in youth settings}

Encourage strategies designed to improve the quantity and quality of physical education for schoolchildren, particularly to increase overall the time children spend being active.

\section{Use marketing and publicity strategies}

Maximise the use of opportunities to generate unpaid or inexpensive publicity, helping to achieve favourable changes in awareness and attitudes.

\section{Use key principles to guide action}

The booklet identifies 11 key principles to guide local action in the promotion of physical activity.

\section{FIGURE 4}

PREVALENCE OF ADEQUATE ENERGY EXPENDITURE BY EDUCATION AND EMPLOYMENT (WEIGHTED TO NSW POPULATION)

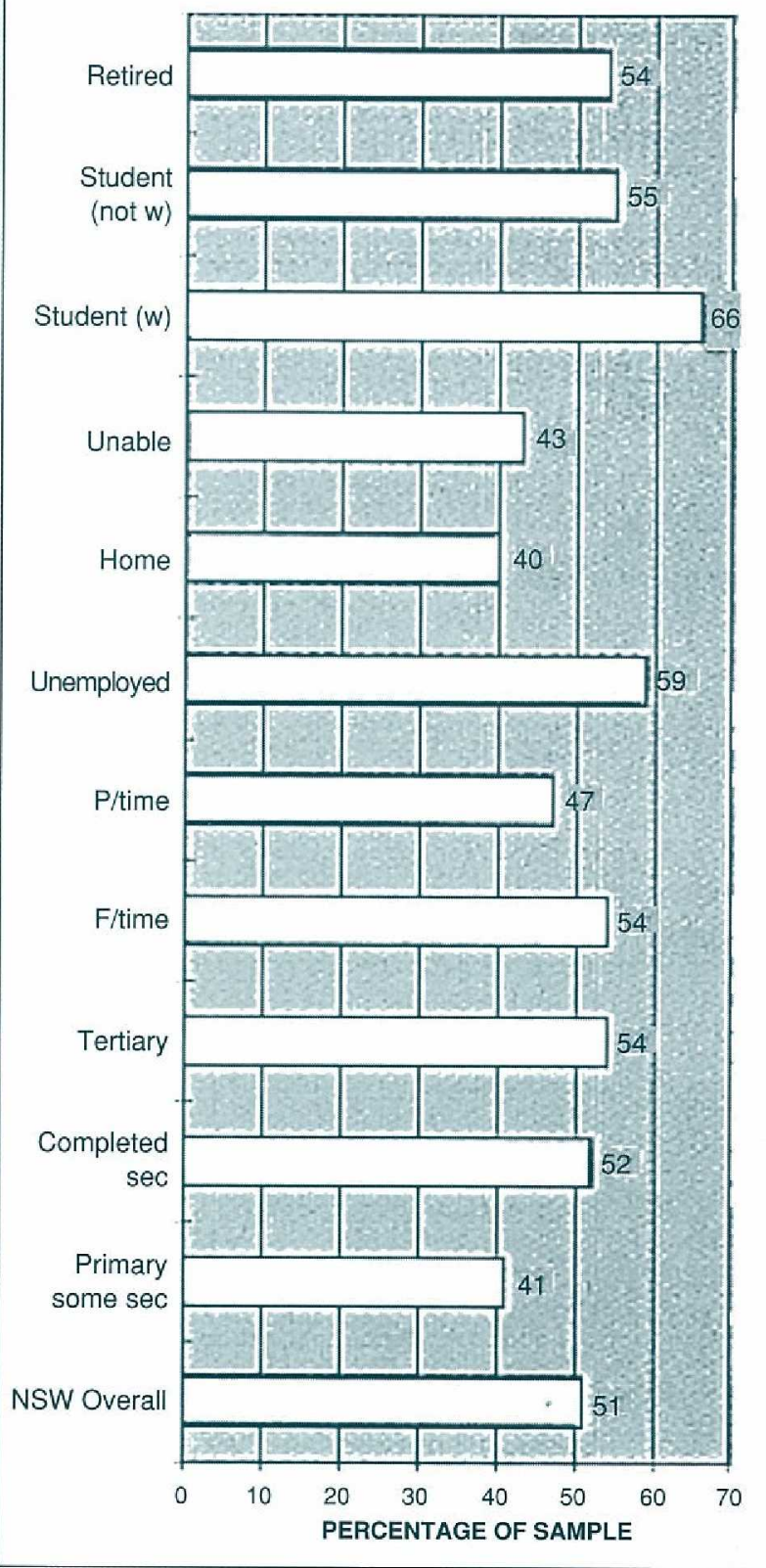

Additional readings in physical activity are suggested, of which Physical Activity and Health: A Report of the Surgeon General, is perhaps the most important ${ }^{1}$. (Professor Steven Blair, an editor of the US Surgeon General's Report, commented on a draft of Towards Best Practice. In July 1995 Professor Blair provided a special briefing on physical activity and public health for the Deputy Premier, Minister for Health and Minister for Aboriginal Affairs, the DirectorGeneral, and the Chief Health Officer of the NSW Health Department.) 


\section{Towards best practice}

$\checkmark$ Continued from page 15

\section{PHYSICAL ACTIVITY DEMONSTRATION PROJECT GRANTS}

The NSW Health Department's Physical Activity

Demonstration Grants Scheme was designed to supplement and enhance the knowledge base required to specify best practice for the promotion of physical activity at Statewide and Area Health Service levels in NSW. Its first phase was implemented in 1996. Priorities for grants are disadvantaged groups, systems and settings, and environments. Each grant is available for a minimum of two years. First-round applications were received from a wide range of organisations in metropolitan and rural NSW, and two projects were funded in the first phase. These are described briefly below.

Evaluation of a general practice intervention - the physical activity prescription

A consortium of three Area Health Services working with local Divisions of General Practice and led by the South

Western Sydney Area Health Service will implement a project entitled A controlled trial of physical activity promotion through general practice. The project is designed to evaluate two different physical activity prescription interventions, aimed at promoting physical activity among general practice patients. The project will concentrate on three Area Health Services - Illawarra, South Western Sydney and Western Sydney.

Working with local councils to modify environments Overcoming the hurdles: removing barriers to women walking in Concord is a partnership project between the Central Sydney Area Health Service and Concord Council. The major aim is to increase by 4.5 per cent the number of women aged 20-50 in the Concord local government area who accumulate 30 minutes or more of walking on most days of the week.

\section{ACTIVE AUSTRALIA}

Active Australia is a collaborative venture between the Australian Sports Commission, the Commonwealth
Department of Health and Family Services, State Departments of Sport and Recreation, local government and the sport and recreation industry. It provides a framework for all physical activity initiatives across the country, which are expected to include a major campaign on physical activity. Subject to Ministerial approval, the first phase of the campaign will begin in NSW in the spring of 1997. The concept of Active Australia was launched on December 11, 1996 by the Federal Minister for Health and Family Services, Dr Michael Wooldridge, and the Federal Minister for Sport, Territories and Local Government and Minister Assisting the Prime Minister for the Sydney 2000 Games, Mr Warwick Smith.

The aspiration of Active Australia is for all Australians to be actively involved in sport, community recreation, fitness, outdoor recreation and other physical activities.

For the health sector, this translates into three specific goals:

- increasing the proportion of Australians involved in regular physical activity; increasing overall the level of physical activity in everyday life; and

- encouraging the provision of quality infrastructure, opportunities and services to support participation in physical activity.

Further information:

Information on Demonstration Project Grants, contact e-mail: pvita@doh.health.nsw.gov.au

The Publication Towards Best Practice for the Promotion of Physical Activity in the Areas of NSW, contact e-mail: bbell@doh.health.nsw.gov.au

For copies of the NSW Physical Activity Task Force Newsletter contact e-mail: bbell@doh.health.nsw.gov.au

Alternatively, for all the above contacts, use facsimile (02) $9391-9579$

The US Surgeon General's Report Physical Activity and Health may be found at Web site http://www.cdc.gov/ nccdphp/sgr/sgr.htm

\section{PUBLIC HEALTH EDITORIAL STAFF}

The editor of the NSW Public Health Bulletin is Dr Michael Frommer, Director, Centre for Research and Development, NSW Health Department. Dr Lynne Madden is production manager.

The Bulletin aims to provide its readers with population health data and information to motivate effective public health action. Articles, news and comments should be 1,000 words or less in length and include a summary of the key points to be made in the first paragraph. References should be set out using the Vancouver style, the full text of which can be found in British Medical Journal 1988; 296:401-5.

Please submit items in hard copy and on diskette, preferably using WordPerfect, to the editor, NSW Public Health Bulletin, Locked Mail Bag 961, North Sydney 2059. Facsimile (02) 93919029.

Please contact your local Public Health Unit to obtain copies of the NSW Public Health Bulletin. The Bulletin can be accessed via the Internet from the NSW Health Department's World Wide Website, at

http://www.health.nsw.gov.au/public-health/phb/phb.html

Back issues can be obtained from the Better Health Centre, Locked Mail Bag 961, North Sydney 2059.

Telephone: (02) 9954 1193, Facsimile (02) 99555196. 